al. (1969) mentioned that a dose of 0.4 to $1.2 \mathrm{~g}$. of clonidine is equivalent to 1.5 to $2.0 \mathrm{~g}$. of methyldopa. These data and our present findings agree on the following points: that $0.7 \mathrm{mg}$. of clonidine corresponds to about $1 \mathrm{~g}$. of methyldopa, that blood-pressure control can be achieved at least as well with clonidine as with methyldopa, and that side effects are more frequent during clonidine than during methyldopa treatment.

The present study compares only clonidine-chlorthalidone to methyldopa-chlorthalidone. To specify the exact place of clonidine of prolonged treatment of hypertension a comparative study of clonidine and other antihypertensive agents is desirable.
REFERENCES

Colwil, J. M., Dutton, A. M., Morrissey, J., and Yu, R. N. (1964). New England fournal of Medicine, 271, 696.

Jungling, K. (1968). Medizinisches Welt, 39, 2105.

Onesti, G., Schwartz, A. B., Kim, K. E., Swartz, C., and Brest, A. N (1969). Circulation, 39, 219.

Seedat, Y. K., Vawda, E. I., Mitha, S., and Ramassar, R. (1969). Lancet, 2, 591.

Smet, G., Hoobler, S. W., Sanbar, S., and Julius, S. (1969). American Heart Fournal, 77, 473.

Smith, W. M., Bachman, B., Galante, J. G., Hanowell, E. G., and Johnson, W. P. (1966). Annals of Internal Medicine, 65, 657.

Wilson, W. R., Okun, R., Tetreault, L., and Fallis, N. (1963). Journal o the American Medical Association, 185, 819.

\title{
Serum Fibrin/Fibrinogen Degradation Products Associated with Postoperative Pulmonary Embolus and Venous Thrombosis
}

\author{
C. V. RUCKLEY,* CH.M., F.R.C.S.ED. ; P. C. DAS, † M.B., B.S., PH.D. ; A. G. LEITCH, $\ddagger$ B.SC. \\ A. A. DONALDSON, $\$ M.R.C.P.ED., D.M.R.D. ; W. A. COPLAND, $\$ V.R.D., F.F.R., D.M.R.D. \\ A. T. REDPATH, $\|$ B.SC., PH.D., A.INST.P. ; P. SCOTTg; J. D. CASH, ${ }^{* *}$ PH.D., F.R.C.P.ED.
}

\begin{abstract}
Gummary: A total of 76 "high-risk" surgical patients were studied for evidence of venous thromboembolic disease. Episodes of deep vein thrombosis and of pulmonary embolism were related to changes in blood levels of fibrin degradation products (F.D.P.). When diagnosed either by ordinary clinical means or by venography and isotope scanning significantly raised F.D.P. levels were found in all cases. Serum F.D.P. estimations are unlikely to help in detecting deep vein thrombosis, but may prove valuable in diagnosing pulmonary embolism.
\end{abstract}

\section{Introduction}

Accurate diagnosis is essential to the evaluation of treatment. Nowhere is this better illustrated than in assessing a widening range of therapy for venous thromboembolic disease. It is now universally recognized that deep vein thrombosis is not reliably detected by clinical examination. Robertson (1968) concluded that the frequency with which venous thrombosis has been diagnosed before death varies between 5 and $26 \%$. This has been confirmed by studies where the diagnosis could be substantiated by necropsy (Gibbs, 1957; Sevitt and Gallagher, 1961; Freiman et al., 1965), isotope studies (Atkins and Hawkins, 1968; Negus et al., 1968), or the use of ultrasonics (Strandness et al., 1967; Sigel et al., 1968).

Pulmonary embolism too is seriously underdiagnosed, and possibly a positive diagnosis before death is made in only 30 to $50 \%$ of cases (Prettin, 1936; Smith et al., 1965). Moreover, patients in whom minor or silent episodes, or both, are left untreated may die from further embolism or extension of thrombi from the original embolus-sequelae which may be prevented by adequate systemic treatment with heparin (Thomas, 1965). Morrell et al. (1963) calculated that between

\footnotetext{
Senior Surgical Registrar, University Department of Clinical Surgery and General Surgical Unit, Western General Hospital, Edinburgh. Registrar, South-East Scotland Regional Blood Transfusion Centre, Royal Infirmary, Edinburgh.

\# Medical Student, Western General Hospital, Edinburgh.

Consultant Radiologist, Western General Hospital, Edinburgh.

II Medical Physicist, Western General Hospital, Edinburgh.

I Laboratory Assistant, South-East Scotland Regional Blood Transfusion Centre, Royal Infirmary, Edinburgh.

* Deputy Director, South-East Scotland Regional Blood Transfusion Centre, Royal Infirmary, Edinburgh.
}

1952 and 1961 at least one preventable death occurred every fortnight in the two major hospitals in Oxford. More recently, in a careful study of 263 right lungs, the same group found evidence of pulmonary emboli in $51.7 \%$ (Morrell and Dunnill, 1968).

Newer methods of diagnosing embolism include pulmonary angiography (Cooley, 1964; Littmann, 1965; Stein et al., 1967), isotope scanning (Wagner et al., 1964; Sabiston and Wolfe, 1967), and ultrasonics (Joyner et al., 1967). These advanced diagnostic techniques demand, in varying measure, considerable expertise, expense, and time. In angiography and isotope work there is some discomfort or risk to the patient, or both. None is ideal as a screening method for routine clinical use, and new and simpler diagnostic aids are urgently required.

During the proteolysis of fibrinogen and fibrin by the fibrinolytic enzyme plasmin several fragments are released which are unclottable and incapable of further digestion (Nussenzweig and Seligmann, 1960; Alkjaersig et al., 1962) Two of these fibrinogen/fibrin degradation products (F.D.P), the so-called $\mathrm{D}$ and $\mathrm{E}$ fragments, have an antigenic determinant which is related to the parent fibrinogen. This property has made it possible to adapt the tanned red cell haemagglutination inhibition immunoassay of Boyden (1951) to estimate serum F.D.P. quantitatively (Murakami, 1965; Merskey et al., 1966) and provide some information on the level of actual in-vivo fibrin deposition and lysis in those clinical states not associated with fibrinogenolysis. This technique is so sensitive that abnormally high values of serum F.D.P. can be detected before there is clear collateral evidence of a depletion of platelets, fibrinogen, and other coagulation factors. Thus immunoassay may be used to show occult intravascular coagulation and fibrinolysis, thereby offering a new approach to the diagnosis of suspected and occult venous thrombosis or pulmonary embolism, or both.

Earlier investigations in this laboratory ascertained the normal range of serum F.D.P. in adults (Das et al., 1967) and in infants and children (Uttley et al., 1969), and further pilot studies in patients after acute myocardial infarction and following surgical operations suggested that the measurement of these polypeptides may be useful in the diagnosis of acute 
occlusive vascular disease (Cash et al., 1969). This paper examines further the relation between serum F.D.P. levels and postoperative deep vein thrombosis and pulmonary embolism.

\section{Patients and Methods}

This study was divided into two parts. In part 1 thromboembolic disease was diagnosed on the basis of physical symptoms and signs aided only by such routine measures as chest radiography and electrocardiography. When this part of the study was completed the results were sufficiently encouraging to suggest that more definite diagnostic methods should be introduced. Thus in part 2 scintillation scanning and venography of the lower limbs and pulmonary scanning were used to supplement the clinical diagnosis.

Part 1 comprised a clinical study on 40 patients before and after major operation. The sexes were included in equal numbers and the mean age of the patients was 60.4 (range 19-80) years. The operations included major abdominal, orthopaedic, and cardiac procedures. Each patient was carefully examined daily for evidence of deep vein thrombosis. The presence of calf pain, tenderness, oedema, dilatation of superficial veins, and temperature differences were recorded. Pulmonary embolism was diagnosed by the usual clinical criteria of chest pain, cyanosis, dyspnoea, and/or haemoptysis supplemented by appropriate radiological and electrocardiographic evidence. Postoperative monitoring was continued for two weeks or so long as the patient remained in hospital. Throughout the period daily samples of venous blood were drawn for estimation of serum F.D.P. Samples were coded to ensure that laboratory staff had no knowledge of the patient's progress. The F.D.P. and clinical assessment were not correlated until some time after the patient had left hospital.

Part 2 comprised 36 cases, and consisted of a continuation of the above protocol supplemented by scintillation scanning of the legs, venography, and lung scanning. The mean age was 56.1 (range 19-81) years. This phase of the project included a group of 10 patients with a clinical diagnosis of pulmonary embolism; these had lung scans, and one or more samples of blood for F.D.P. estimation were drawn as soon as possible after the acute episode.

Scintillation scanning of the legs with ${ }^{125}$ I fibrinogen was carried out by the method of Negus et al. (1968). Venography was performed by the ascending route, except in two patients in whom pertrochanteric intraosseous injections were used. For the lung scans indium-113m ferric hydroxide scanning agent was used. A supine chest $x$-ray film was also obtained for correlation with the scan (Goodwin et al., 1968). Areas of reduced or absent isotope uptake over the lung

\begin{tabular}{|c|c|c|c|c|}
\hline \multirow{2}{*}{ Diagnosis } & \multirow{2}{*}{ No. of Cases } & \multicolumn{2}{|c|}{ Peak F.D.P. $(\mu \mathrm{g} . / \mathrm{ml})}$. & \multirow{2}{*}{ Significance } \\
\hline & & Mean \pm S.D. & Range & \\
\hline No D.V.T. & 22 & $31 \cdot 8 \pm 2 \cdot 4$ & $16 \cdot 8-55 \cdot 7$ & $P<0.001$ \\
\hline D.V.T. & 15 & $57 \cdot 4 \pm 5 \cdot 5$ & $35 \cdot 8-111 \cdot 4$ & \\
\hline P.E. & 3 & $234 \cdot 8 \pm 116 \cdot 0$ & $102 \cdot 2-466 \cdot 0$ & $P<0.002$ \\
\hline
\end{tabular}

D.V.T. $=$ Deep vein thrombosis. P.E. $=$ Pulmonary embolism.

TABLE II.-Diagnosis by Isotope Scan and Venography

\begin{tabular}{|c|c|c|c|c|}
\hline \multirow{2}{*}{ Diagnosis } & \multirow{2}{*}{ No. of Cases } & \multicolumn{2}{|c|}{ Peak F.D.P. $(\mu \mathrm{g} . / \mathrm{ml})}$. & \multirow{2}{*}{ Significance } \\
\hline & & Mean \pm S.D. & Range & \\
\hline No D.V.T. & 7 & $25 \cdot 4 \pm 3 \cdot 9$ & $6 \cdot 0-37 \cdot 1$ & \\
\hline D.V.T. & 13 & $48 \cdot 9 \pm 6 \cdot 6$ & $20 \cdot 3-112 \cdot 0$ & \\
\hline P.E. proved & 10 & $138 \cdot 5 \pm 29 \cdot 0$ & $40 \cdot 6-296 \cdot 0$ & 000 \\
\hline P.E. disproved & 6 & $36 \cdot 6 \pm 6 \cdot 1$ & $16 \cdot 8-51 \cdot 1$ & 002 \\
\hline
\end{tabular}

fields were taken to represent lung lesions. The presence of such lesions was interpreted, in the light of the radiological and clinical findings, as indicating pulmonary embolism. The serum F.D.P. assay was performed as described previously (Das et al., 1967).

\section{Results}

It has proved difficult to relate a measurement based on a daily blood sample to the evolution of a thrombotic and/or embolic process whose onset and magnitude could not be defined in precise terms. The highest F.D.P. values obtained during the period of study in each patient ("peak F.D.P.") have been grouped, for each part of the study, according to whether he or she had (1) no thromboembolism, (2) deep vein thrombosis, or (3) pulmonary embolism. (Tables I and II and Figs. 1 and 2.)

\section{Part 1}

In $22(55 \%)$ patients there was no clinical evidence of deep vein thrombosis, and deep vein thrombosis was diagnosed in 15 , of whom three showed signs of ileofemoral thrombosis. Three patients were diagnosed as having pulmonary emboli, and in these the signs of deep vein thrombosis did not

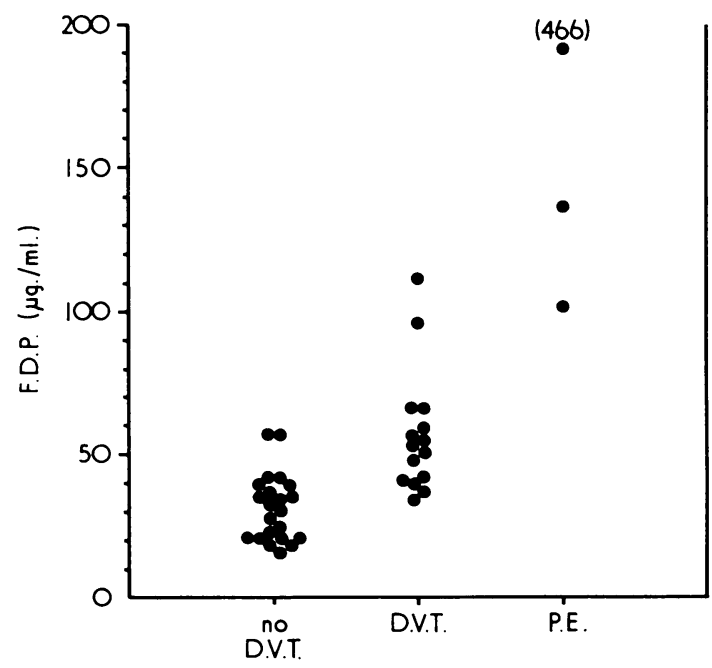

FIG. 1.-Peak F.D.P. levels in 37 patients in whom the diagnosis of thromboembolic disease was made by routine clinical methods.

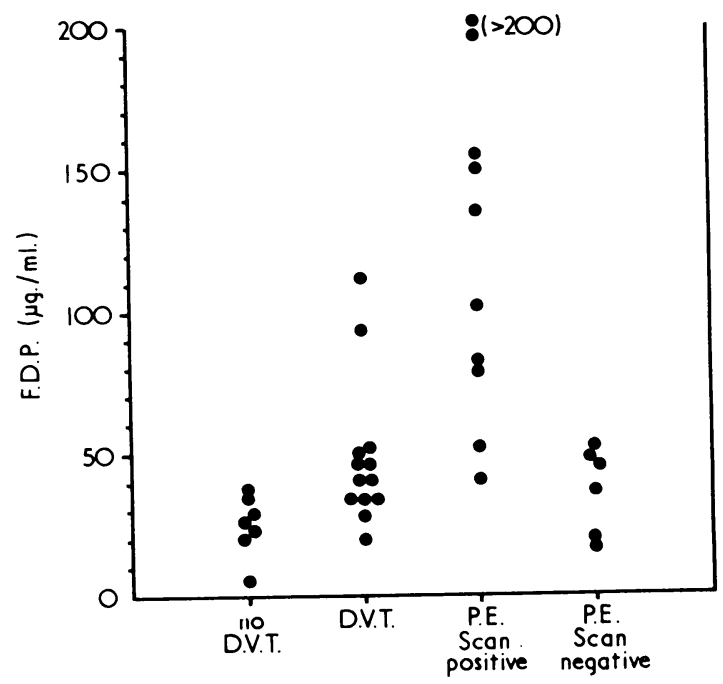

FIG. 2.-Peak F.D.P. levels in 36 patients in whom venography and isotope scanning were used to make the diagnosis of thrombosis or embolism. 
become apparent until some time after he pulmonary symptoms. One patient in the latter group dled of further embolism three weeks after the completion of this study.

The scatter of peak F.D.P. levels in these patients is shown in Fig 1. The significance of differences between means of each group as determined by Student's $t$ tests is shown in Table I. The differences are highly significant.

\section{Part 2}

The findings in the 26 patients studied in the postoperative period were as follows: 6 were diagnosed as having deep vein thrombosis with pulmonary embolism, 13 as deep vein thrombosis alone, and $7(27 \%)$ as free of thromboembolism. In addition, the diagnosis was confirmed by lung scanning in 4 of the 10 patients referred with a clinical diagnosis of embolism. Thus 10 patients in all are classed as "pulmonary embolism proved" (Table II).

Diagnostic Aids.-Bilateral Scintillation Scanning was performed 89 times on 22 patients. Positive scans were obtained in 15 patients $(68 \%)$. In two both legs were positive. Venography was performed on 10 patients. Six of these had had scans, of which five were positive and one was equivocal. The latter patient had a raised count in the left upper thigh. He had had a pelvic colectomy, and ascending venography failed to show any thrombus in this area; hence it was concluded that increased blood flow in the area, as a consequence of pelvic surgery, accounted for the raised count. One patient whose calf scan was positive had a negative venogram; it was suspected that the venogram had failed to outline a thrombosed venous sinusoid. In every other instance the site of the clot shown on venography corresponded to the "hot" area on scintillation scanning. Though venography was not performed in patients in whom there was no reason to suspect thrombosis some control data were provided by the fact that when venography was performed it was invariably bilateral. In contralateral legs there was no instance of a positive venogram where scintillation scanning had been negative. The overall agreement between scans and venography was $90 \%$.

F.D.P.-The scatter of results in deep vein thrombosis negative and positive groups and also in the pulmonary embolism negative and positive groups are shown in Fig. 2 and Table II. The latter two groups include the 10 patients who were referred with a clinical diagnosis of pulmonary embolism, ranging in severity from minimal disability to severe pain and shock. Pulmonary embolism negative (Fig. 2), or disproved (Table II), indicates that subsequent investigations, including lung scanning, failed to substantiate the initial clinical diagnosis. In the positive, or proved, group it was not possible to determine, especially in the minor episodes, precisely how much earlier embolism had taken place. The interval was judged to range from 15 minutes to 48 hours.

Deep Vein Thrombosis.-A striking increase in the proportion of patients with deep vein thrombosis was noted in part 2. Combining the results of scintillation scanning and venography gave a detection rate of $73 \%$ in contrast to the $45 \%$ found by clinical examination in part 1. High-risk patients were sought throughout and there was no change in the policy of selection between the two parts. In the thrombosis-free group the mean peak F.D.P. was $25.4 \mu \mathrm{g} . / \mathrm{ml}$.; in the thrombosis-positive group it was $48.9 \mu \mathrm{g} . / \mathrm{ml}$. (Table II). These means were significantly different by Student's $t$ test $(P<0.05)$. When clinical features of deep vein thrombosis appeared in these patients they were always noted one or more days after the peak F.D.P. had been reached.

Pulmonary Embolism.-Patients with a clinical diagnosis of pulmonary embolism in whom the lung scan was reported by the radiologist either as unequivocally "positive" (7) or "compatible with pulmonary embolism" (3) had a mean peak F.D.P. of $138.5 \mu \mathrm{g} . / \mathrm{ml}$. Those in whom the scan was negative (6) had a mean peak F.D.P. of $36.6 \mu \mathrm{g} . / \mathrm{ml}$. These means were significantly different $(P<0.002)$. With the exception of two cases there was no overlap between the ranges of these two groups, but considerable overlap did occur between the deep vein thrombosis positive group and the pulmonary embolism positive group (Fig. 2).

\section{Case Reports}

In two instances during this study it was thought to be in the patient's interest to break the secrecy to obtain prompt laboratory reports. The two cases are summarized to illustrate the potential value of these measurements.

\section{Case 1}

A married woman aged 59 underwent posterior rhizotomy in May 1969 for intractable left thoracotomy pain. After this she developed transient paraplegia. Signs of deep vein thrombosis were noted in the right leg 15 days after operation and warfarin was prescribed. Two days later she developed breathlessness and cyanosis with return of left chest pain, which she said was similar to her thoracotomy pain. Chest radiography and electrocardiography were unhelpful, but isotope scan confirmed the clinical diagnosis of pulmonary embolism. Heparin therapy was started. Daily sampling of the blood for F.D.P. estimation was begun six hours after the acute episode.

During the ensuing three weeks she complained repeatedly of left chest pain, and it was not clear whether this was due to thoracotomy, embolism, or psychiatric causes. The heparin was discontinued after three days but warfarin was continued. On the 35 th postoperative day she complained of further left-sided chest pain, which seemed more severe than before. Serum F.D.P. estimations were therefore performed urgently by the laboratory. A peak of $89 \mu \mathrm{g} . / \mathrm{ml}$. was reported immediately after her first acute episode, a peak of $134 \mu \mathrm{g} . / \mathrm{ml}$. coincided with her second episode, and the intervening values did not exceed $50 \mu \mathrm{g} . / \mathrm{ml}$. This was interpreted as indicating further pulmonary embolism, and heparin therapy was reintroduced. A second lung scan two days later showed a large area of absent isotope uptake which had not been present on the previous scan. The complete series of F.D.P.s estimated several weeks later as part of this study is shown in Fig. 3.

\section{Case 2}

A married woman aged 36 was readmitted to hospital two weeks after tonsillectomy. She complained of severe pleuritic left chest pain of sudden onset. She had no haemoptysis. There was slight tenderness of both calves but no dilatation of superficial veins, temperature difference, or oedema. Chest radiography showed no opacity and an electrocardiogram was unhelpful. A diagnosis of pulmonary embolism was made and a course of heparin and warfarin started. When on the fifth day after admis-

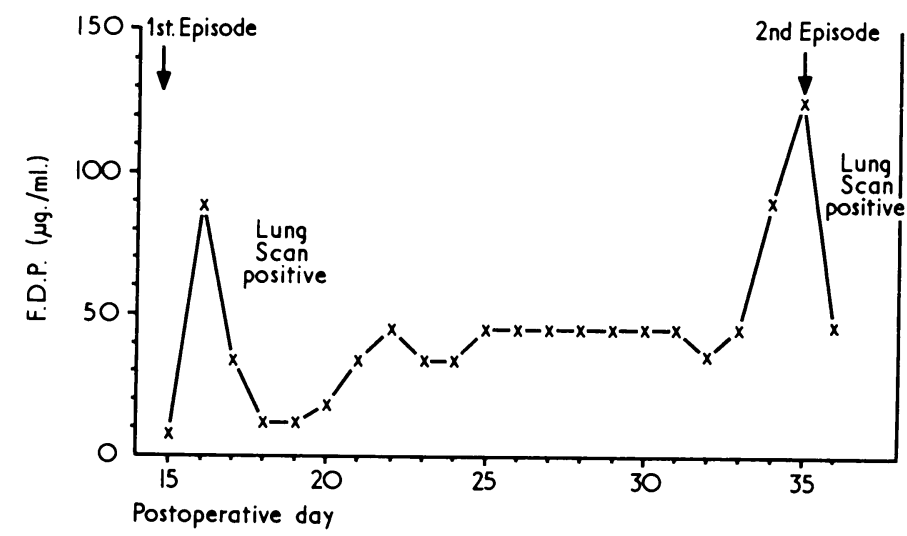

FIG. 3.-Daily F.D.P. measurements in Case 1 (see text). This patient had 
sion a lung scan was found to be negative the diagnosis was reviewed and the question of stopping the anticoagulant therapy was raised. Blood samples had been obtained since admission and it was decided in this instance not to delay the laboratory estimations. The highest level of F.D.P. in six daily samples was $16.8 \mu \mathrm{g} . / \mathrm{ml}$. Thus the diagnosis of pulmonary embolism was excluded, the anticoagulants were stopped, and the patient was discharged with a final diagnosis of pleurodynia.

\section{Discussion}

If our belief that by clinical examination we underdiagnose thromboembolic disease is correct, and if the presence and extent of thrombosis are correlated with the levels of F.D.P. in the blood, then certain differences between the findings in the two parts of this study would be predictable. These would include (1) a lower proportion of "thrombosis-free" patients when more accurate diagnostic aids were invoked (part 2), assuming no change in selection of patients during the study; (2) a lower mean peak F.D.P. in the thrombosisfree patients in the latter group, since the corresponding group in part 1 must have included several cases where thrombosis was present but undetected; and, for the same reason, (3) a higher mean peak F.D.P. in the deep vein thrombosis positive group in part 1 , since only the cases of more extensive thrombosis were likely to be diagnosed by clinical examination. Each of these assumptions is supported by the data.

We have reported the levels of F.D.P. as measured in the sera of 106 normal subjects and considered the evidence that such measurements might be correlated with continuing intravascular coagulation and fibrinolysis (Das et al., 1967). Subsequent studies have shown that several conditions may produce moderate rises in F.D.P. In the postoperative patient, however, our current experience would suggest that, provided the clinician can exclude acute renal failure, acute and extensive arterial obstruction, and those conditions known to be associated with disseminated intravascular coagulation (McKay, 1965), a rise in F.D.P. above $100 \mu \mathrm{g} . / \mathrm{ml}$. is very strong presumptive evidence of pulmonary embolism.

In part 2 of this study one patient in the deep vein thrombosis group showed a peak F.D.P. of $112 \mu \mathrm{g} . / \mathrm{ml}$. This patient, who had extensive ileofemoral thrombosis, was suspected of having possible pulmonary embolus, though she did not show specific diagnostic features, and on two occasions lung scans were attempted but failed for the technical reasons mentioned earlier. This patient could not therefore be included in the "proved pulmonary embolism" group. Thus it is uncertain whether the high F.D.P. levels in this and other cases do reflect the extensive nature of the deep vein thrombosis or, alternatively, indicate a failure to diagnose a number of pulmonary emboli. The work of Morrell and Dunnill (1968) certainly suggested the latter as a likely explanation. Another supporting observation is that, while high F.D.P. peaks could generally be related to recognizable acute pulmonary episodes, several peaks were also noted at times when there were no obvious change in the patient's condition. We believe that these peaks may represent silent pulmonary emboli.

The rises in F.D.P. associated with pulmonary emboli were very transient and usually returned to normal or near-normal levels within 24 hours. Therefore, though four patients in the pulmonary embolism proved group showed relatively low peak F.D.P. levels of between 41 and $81 \mu \mathrm{g} . / \mathrm{ml}$., until we can determine exactly when the embolism occurs we cannot be certain of the significance of these figures. If a patient with pulmonary embolism collapses with central chest pain, dyspnoea, cyanosis, shock, and raised central venous pressure we may reasonably assume that the features are an immediate sequel to the arrival of the embolus in the lungs. If, on the other hand, the patient is first suspect 1 of having pulmonary embolism on the basis of haemoptysis and/or chest pain of pleuritic type with dyspnoea and cyanosis of gradual onset, the diagnosis may be two to three days late. Three of the four patients with the low F.D.P. levels in the pulmonary embolism proved group were referred with symptoms of the latter type, and probably higher levels of F.D.P. were missed. The limitations of such measurements as a screening test and the limited value of single blood samples are thus shown. Further work is necessary to relate the timing of the acute episode more accurately to the changes in serum F.D.P.

While the measurement of serum F.D.P. will probably prove to be of value as a further aid in diagnosing occult and clinically evident pulmonary embolus, the position with regard to venous thrombosis is less certain. Though the rise in serum F.D.P. in the deep vein thrombosis proved group was significantly greater than in the controls, it is considered, at least postoperatively to be insufficient to be of real clinical value. Nevertheless, further developments in those techniques designed to detect and measure the in-vivo end-products of coagulation or fibrinolysis, or both, may prove to be more sensitive and specific.

We should like to thank the following surgeons for their cooperation in allowing us to study patients under their care: $\mathrm{Mr}$. C. W. A. Falconer, Mr. W. P. Small, and Mr. A. N. Smith, Surgical Unit, Western General Hospital, Edinburgh; and Dr. W. R. Waddell, Chairman of the Department of Surgery, University of Colorado Medical Centre, Denver, Colorado. Our thanks are also due to Dr. R. A. Cumming, Director, S.-E. Scotland Regional Blood Transfusion Centre, for his continued encouragement and guidance. This research programme was supported by a grant from the Scottish Hospital Endowments Research Trust.

REFERENCES

Alkjaersig, N., Fletcher, A. P., and Sherry, S. (1962). fournal of Clinical

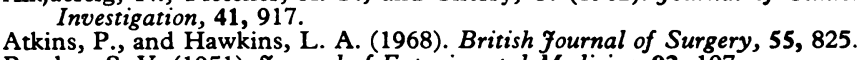

Boyden, S. V. (1951). Fournal of Experimental Medicine, 93, 107.

Cash, J. D., Woodfield, D. G., Das, P. C., and Allan, A. G. E. (1969). British Medical fournal, 2, 576.

Cooley, R. N. (1964). American fournal of Roentgenology, Radium Therapys and Nuclear Medicine, 92, 693.

Das, P. C., Allan, A. G. E., Woodfield, D. G., and Cash, J. D. (1967). British Medical fournal, 4, 718.

Freiman, D. G., Suyemoto, J., and Wessler, S. (1965). New England fournal of Medicine, 272, 1278.

Gibbs, N. M. (1957). British fournal of Surgery, 45, 209.

Goodwin, D. A., Stern, H. S., and Wagner, H. N. (1968). Journal of the American Medical Association, 206, 339.

Joyner, C. R., Miller, L. D., Dudrick, S. J., Eskin, D. J., and Bloom, P. (1967). Transactions of the American Clinical and Climatological Association, $78,28$.

Littmann, D. (1965). In Pulmonary Embolic Disease, ed. A. A. Sasahara, and M. Stein, p. 186. New York, Grune and Stratton.

McKay, D. G. (1965). Disseminated Intravascular Coagulation. New York, Harper and Row.

Merskey, C., Kleiner, G. J., and Johnson, A. J. (1966). Blood, 28, 1.

Morrell, M.' T., and Dunnill, M. S. (1968). British łournal of Surgery, 55, 347.

Morrell, M. T., Truelove, S. C., and Barr, A. (1963). British Medical fournal, 2,830 .

Murakami, M. (1965). Japanese fournal of Clinical Pathology, 13, 542.

Negus, D., Pinto, D. J., Le Quesne, L. P., Brown, N., and Chapman, M. (1968). British fournal of Surgery, 55, 835.

Nussenzweig, V., and Seligmann, M. (1960). Revue d'Hématologie, 15, 451.

Prettin, F. (1936). Virchows Archiv für pathologische Anatomie und Physiologie und für Klinische Medizin, 297, 535.
low

Robertson, B. (1968). Acta Chirurgica Scandinavica, Suppl. No. 387, p. 27.

Sabiston, D. C., and Wolfe, W. G. (1967). Annual Review of Medicine, 18, 443.

Sevitt, S., and Gallagher, N. (1961). British fournal of Surgery, 48, 475.

Sigel, B., et al. (1968). Surgery, 64, 332.

Smith, G. T., Dexter, L., and Dammin, G. J. (1965). In Pulmonary Embolic Disease, ed. A. A. Sasahara and M. Stein, p. 120. New York, Grune and Stratton.

Stein, P. D., et al. (1967). American Heart fournal, 73, 730.

Stein, P. D., et al. (1967). American Heart fournal, 73, 730 . (1967). American fournal of Surgery, 113, 311.

Thomas, D. P. (1965). New England fournal of Medicine, 273, 885.
Uttley, W. D., Allan, A. G. E., and Cash, J. D. (1969). Archives of Disease in Childhood, 44, 761 .

Wagner, H. N., Sabiston, D. C., McAfee, J. G., Tow, D., and Stern, H. S. (1964). New England fournal of Medicine, 271, 377. 